\title{
EFFECT OF ALTERNATIVE FUELS ON DIESEL LOW TEMPERATURE COMBUSTION
}

\author{
SANZ-ARGENT J. \\ HERNÁNDEZ J.J.* \\ BALLESTEROS R.
}

Grupo de Combustibles y Motores

Departamento de Mecánica Aplicada e Ingeniería de Proyectos

Universidad de Castilla-La Mancha

Av. Camilo José Cela s/n, 13071 Ciudad Real, Spain

Received: 30/01/2013

Accepted: 26/04/2014

*to whom all correspondence should be addressed:

Available online: 29/05/2014

e-mail: JuanJose.Hernandez@uclm.es

\section{ABSTRACT}

A set of experiments have been carried out in a heavy duty single cylinder engine using high $E G R$ rates and different start of injection angles (SOI). Three different fuels (conventional diesel fuel, a dieselethanol mixture (e-diesel) and a Fischer-Tropsch fuel (GTL)) have been tested in order to evaluate their potential to achieve Low Temperature Combustion (LTC) conditions. Diesel and e-diesel have shown poor repeatability for the most delayed angle (4 deg aTDC) due to significant cycle-to-cycle variations. GTL has shown a heat release rate pattern typical of conventional diesel combustion for all the SOI values, while diesel and e-diesel show fully premixed combustion for delayed SOI (from 4 deg bTDC). A delay of $\mathrm{SO}$ causes a decrease in the brake thermal efficiency and an increase in THC and CO emissions, the latter being more important when e-diesel is used. While late injection seems to considerably improve NOx emissions, no benefits have been obtained for diesel particles, maybe due to the low engine torque tested (which causes the soot production rate to be more significant than the oxidation rate). The low autoignition tendency together with the high volatility of ethanol makes e-diesel as a promising fuel to achieve LTC conditions while keeping acceptable fuel consumption and CO/THC emissions.

Keywords: Alternative diesel fuels, Low Temperature Combustion, Pollutants emission

\section{Introduction}

In order to accomplish the very restrictive pollutant regulations currently in force, it is necessary not only the use of post-treatment devices in vehicles (particle traps, diesel oxidation catalyst, lean NOxTraps) but also the improvement of the combustion process. In the case of compression ignition engines, a family of new combustion concepts (usually known as LTC modes) is currently being developed.

The most common approach for diesel LTC (Low Temperature Combustion) is the attainment of a highly premixed mixture prior to combustion, which allows the simultaneous reduction of NOx and PM (Particulate Matter). This mixture may be obtained by the use of a very advanced injection, creating an almost homogeneous mixture due to the long ignition delay caused by the low temperature inside the engine cylinder. This approach is commonly known in the literature as $\mathrm{HCCl}$ (Homogeneous Charge Compression Ignition), and it has been explored by many researchers for both gasoline-like fuels (the work of Onishi et al., (1979) being the first one analyzing the possibilities of this type of combustion) and diesel like fuels (the early work of Thring ,(1989) showing the potential and challenges of this combustion for diesel fuels). However, several problems such as the jet impingement on the cylinder 
wall, leading to high CO and THC emissions (Jacobs et al., 2007), or serious knock at high loads prevents $\mathrm{HCCl}$ to be the best LTC approach.

An alternative for obtaining a highly premixed mixture is the use of late injection (even after the Top Dead Center, aTDC) and high Exhaust Gas Recirculation (EGR) rates. This technique was firstly proposed by Kimura et al., (1999) and it has been successfully used in commercial engines (Zhao et al., 2003). The injection of the fuel during the expansion stroke together with high $E G R$ rates increases the ignition delay. As a consequence, combustion starts when most of the fuel has been introduced in the combustion chamber and the process develops in a totally different manner when compared with conventional diesel combustion. Musculus et al., (2013) have recently proposed a conceptual model for this type of combustion, similarly as that previously developed by Dec, (1997) for traditional diesel combustion. Combustion initiates when the fuel has already been mixed with the oxidant (thus the mixing-controlled phase not being significant) and the combustion temperature is quite low, both aspects causing the simultaneous reduction of PM and NOx emissions (Jacobs et al., 2007; Fang et al., 2009; Genzale et al., 2010). Although brake thermal efficiency is deteriorated due to the shift of combustion, this effect is partially compensated by lower heat losses, keeping fuel consumption similar to that obtained with traditional diesel modes (Kimura et al., 1999).

Even though there are many works already published in the literature focused on delayed combustion using diesel fuel, the particularities of this mode using alternative fuels have not been yet deeply studied. Kalghatgi et al., (2006) analyzed the behaviour of gasoline and several diesel fuels with different cetane number and they concluded that high resistance autoignition fuels are good candidates for this type of combustion. Fang et al., (2008) explored the possibilities of soybean biodiesel for LTC combustion, achieving high NOx reductions although no PM results were presented in their work. Karra et al., (2008) tested several diesel-biodiesel fuels under LTC conditions, and they showed simultaneous reduction of NOx and PM for delayed injection. This study pretends to provide some insight about the use of other alternative fuels such as e-diesel and GTL, both of them with a high future interest.

\section{Procedure}

All the tests were carried out in a research single-cylinder engine test bench (Figure 1). The testing bench consists of an AVL 501 single-cylinder connected to a Piller 225.26B dynamometric brake. The technical specifications of the engine are shown in Table 1 . All the auxiliary systems (such as the intake, exhaust, refrigeration, lubrication and common-rail injection systems) can be controlled individually. Regulated gaseous pollutant emissions such as $\mathrm{NO}_{\mathrm{x}}, \mathrm{CO}$, and total hydrocarbons (THC) were measured with an Environnement S.A equipment. Particle matter emissions were measured with a dilution sampling system NOVA MESS TECHNIK, while the particle size distribution was analyzed by a Scanning Mobility Particle Sizer (SMPS) manufactured by TSI.

Table 1. Technical specifications of the single-cylinder engine.

\begin{tabular}{cc}
\hline Parameter & Value \\
\hline Cylinder volume & $1999 \mathrm{~cm}^{3}$ \\
\hline Compression ratio & 15.78 \\
\hline Bowl volume & $101 \mathrm{~cm}^{3}$ \\
\hline \# of inlet valves & 2 \\
\hline \# of exhaust valves & 2
\end{tabular}

The in-cylinder pressure was measured with a piezoelectric pressure transducer (Kistler 6041A), the chamber pressure signal being monitored with the data acquisition system YOKOGAWA OR1400. For each experiment, 20 consecutive pressure traces were recorded and averaged. The Heat Release Rate $(H R R)$ has been calculated from the averaged pressure signal through a thermodynamic diagnostic model, described in Lapuerta et al., (1999). 


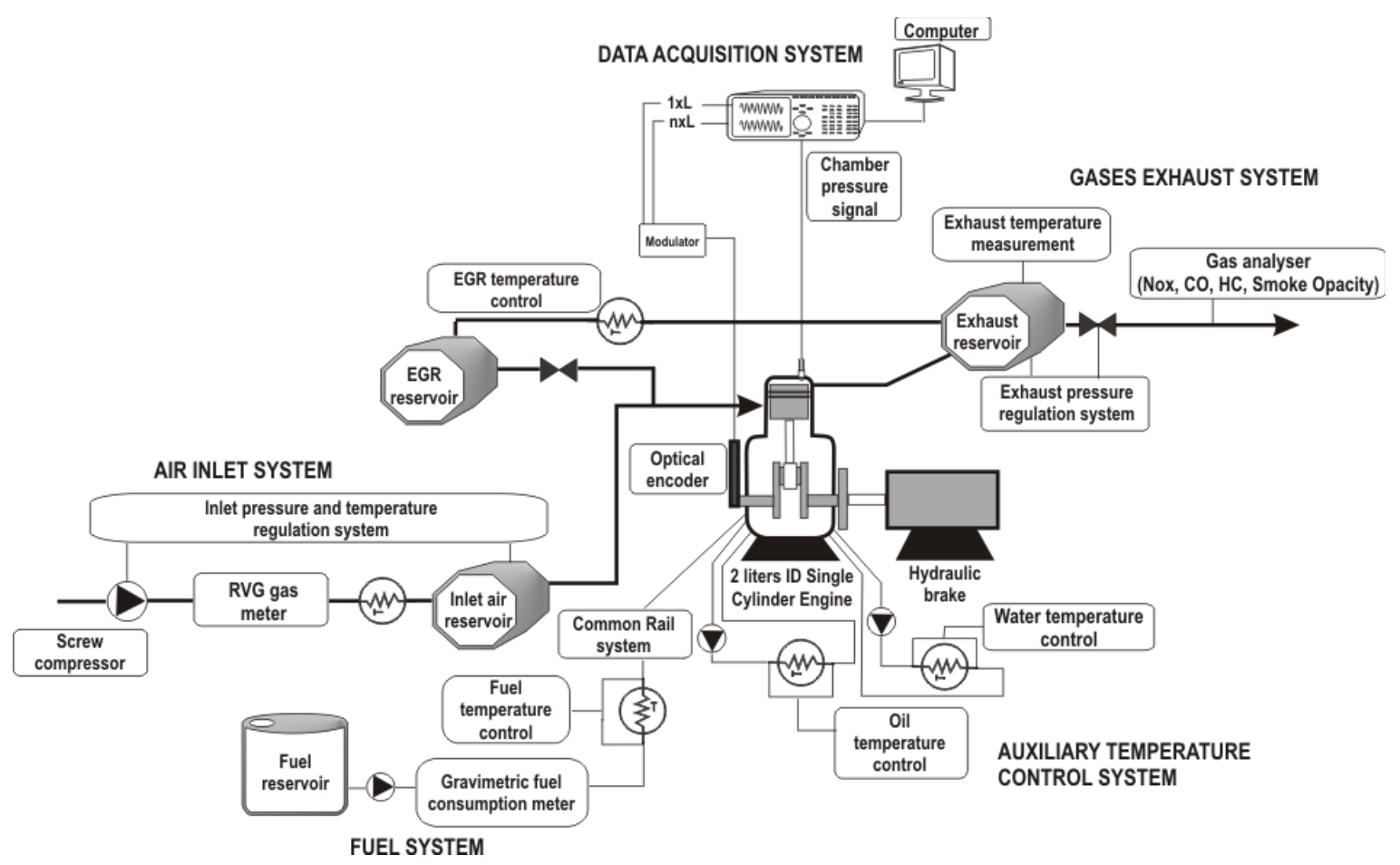

Figure 1. Scheme of the experimental installation

Three different fuels have been used in the tests: a commercially available diesel fuel provided by CEPSA (Spanish Petroleum Company), a mixture of diesel and ethanol (10\% in volume, e-diesel) and a FischerTropsch fuel (GTL) provided by SASOL. Table 2 shows the main properties of the fuels. It can be observed that the alternative fuels selected show either higher or lower values than diesel fuel for the most significant properties: heating value and cetane number (GTL showing the highest values for both cases while e-diesel showing the lowest).

Table 2. Fuels properties

\begin{tabular}{cccc}
\hline & diesel & e-diesel & GTL \\
\hline Density @ $15^{\circ} \mathrm{C}\left(\mathrm{kg} \mathrm{m}^{-3}\right)$ & 845 & 839.44 & 774 \\
\hline Viscosity @ 40ㅇ $(\mathrm{cSt})$ & 2.51 & 2.26 & 2.34 \\
\hline LHV $\left(\mathrm{MJ} \mathrm{kg}^{-1}\right)$ & 42.43 & 40.84 & 44.03 \\
\hline Water content $(\mathrm{ppm} \mathrm{w})$ & 70.0 & 471.0 & 20.0 \\
\hline $\mathrm{CFPP}\left({ }^{\circ} \mathrm{C}\right)$ & -16 & -13 & -7 \\
\hline Formula & $\mathrm{C}_{14.62} \mathrm{H}_{26.87} \mathrm{O}_{0.08}$ & $\mathrm{C}_{10.65} \mathrm{H}_{20.3} \mathrm{O}_{0.37}$ & $\mathrm{C}_{16.89} \mathrm{H}_{35.77}$ \\
\hline $\mathrm{C}(\% \mathrm{w} / \mathrm{w})$ & 86.14 & 83.58 & 84.82 \\
\hline $\mathrm{H}(\% \mathrm{w} / \mathrm{w})$ & 13.20 & 13.16 & 15.18 \\
\hline $\mathrm{O}(\% \mathrm{w} / \mathrm{w})$ & 0.66 & 3.26 & 0.0 \\
\hline Aromatic content $(\% \mathrm{w} / \mathrm{w})$ & 29.8 & 27.0 & 0.0 \\
\hline Molecular weight $\left(\mathrm{g} \mathrm{mol}{ }^{-1}\right)$ & 203.7 & 154.3 & 238.9 \\
\hline $\mathrm{H} / \mathrm{C} \mathrm{ratio}$ & 1.84 & 1.91 & 2.12 \\
\hline Cetane Number & 54.2 & 40.0 & 89.2 \\
\hline
\end{tabular}

(a) Averaged on molar basis

A high and constant $E G R$ rate (40\%) was used in all the tests, while the start of injection was retarded trying to keep the combustion stability. The engine operating conditions selected for the experiments are shown in Table 3 ( $M_{e}$ being the engine torque, $p_{i n}$ and $T_{\text {in }}$ the intake pressure and temperature respectively, and $p_{\text {rail }}$ the injection pressure). These conditions were selected in order to achieve long ignition delay times (by using high EGR rates and delayed injection timings) while keeping stable combustion and acceptable engine efficiencies. Since the LTC modes are mainly used at low-medium 
load conditions (to avoid very poor engine efficiency when using delayed injection), the engine torque tested corresponds approximately to $50 \%$ of full load operation (at $1500 \mathrm{rpm}$ ).

Table 3. Engine operating conditions

\begin{tabular}{ccccccc}
\hline $\boldsymbol{M}_{\boldsymbol{e}}[\mathrm{Nm}]$ & $\boldsymbol{n}[\mathrm{rpm}]$ & $\boldsymbol{p}_{\text {in }}[\mathrm{bar}]$ & $\boldsymbol{T}_{\text {in }}\left[{ }^{\circ} \mathrm{C}\right]$ & $\boldsymbol{p}_{\text {rail }}[\mathrm{bar}]$ & $\boldsymbol{E G R}$ & SOI [CAD] \\
\hline 70 & 1500 & 1.2 & 35 & 1200 & $40 \%$ & from 12 bTDC to 4 aTDC \\
\hline
\end{tabular}

\section{Results}

\subsection{Combustion analysis}

The most delayed $\mathrm{SOI}$ angle led to poor repeatability in the case of diesel fuel and e-diesel due to large cycle-to-cycle variations. GTL presented acceptable repeatability even for much delayed injection as a consequence of its high cetane number. Figure 2 shows the pressure traces from 20 consecutive cycles for the experiments carried out at 4 deg aTDC using diesel fuel (after reaching stationary conditions). As can be seen in the figure, while the compression stroke shows a very good repeatability, the start of combustion (SOC) may vary up to 5 CAD. Such differences may be attributed to the high sensitivity of the combustion process to the intake thermodynamical conditions and/or to the wall heat transfer. For that reason, the values from diesel and e-diesel at the most delayed SOI (4 deg aTDC) have not been included in this work.

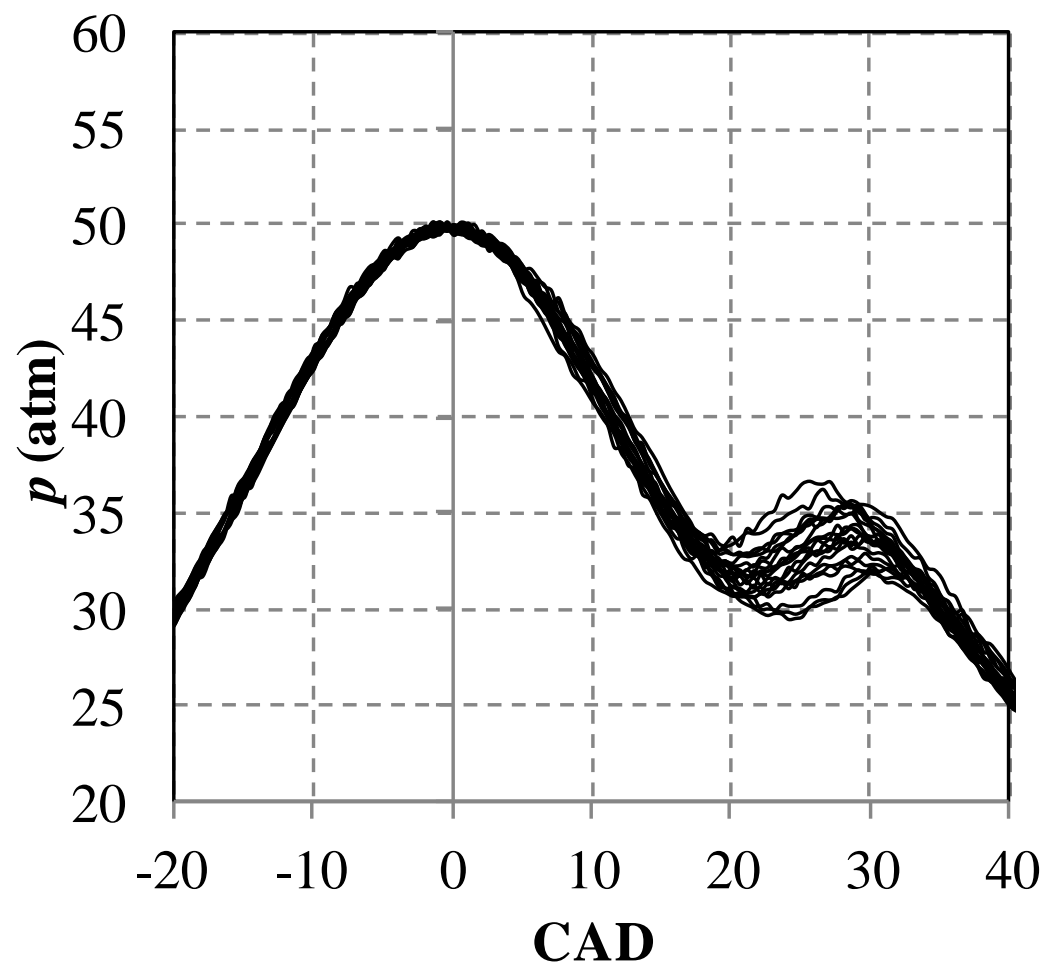

Figure 2. Consecutive pressure traces at stationary conditions ( $\mathrm{SOI}=4 \mathrm{deg}$ aTDC, diesel fuel)

The HRR trace of each experiment is characterized using two global parameters: ignition delay (ID) and the weight of the premixed combustion on the whole combustion process. $I D$ is defined as the time between the $\mathrm{SOI}$ and the $S O C$, while \% premixed is defined as the heat released during the premixed combustion phase with respect to the total heat released. Figure 3 describes graphically the parameters used in this work. 


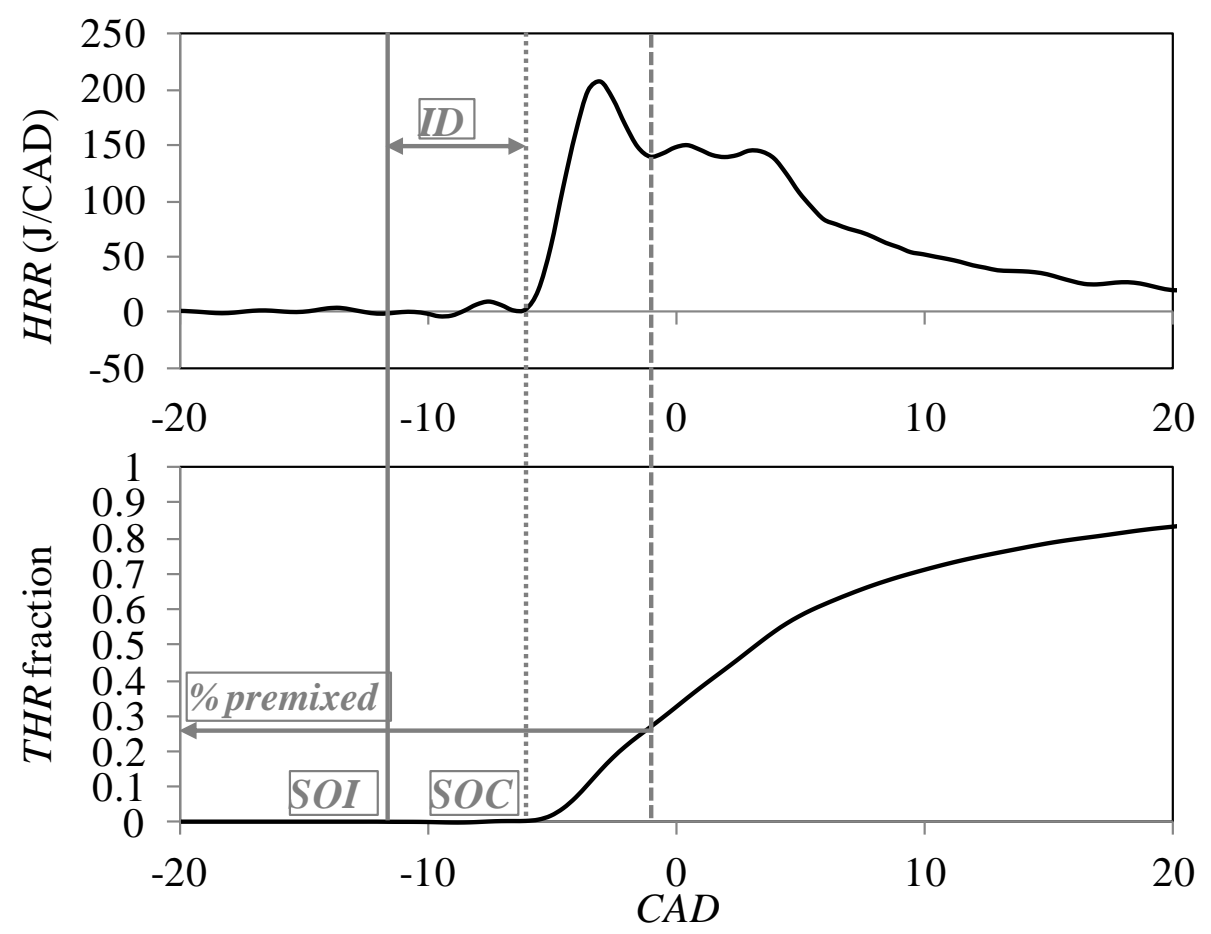

Figure 3. Definition of the global parameters obtained from a $H R R$ trace

Figure 4 shows the results from all the experiments carried out. As can be seen in the figure, the shortest values of $I D$ were obtained for GTL, causing combustion to proceed as a traditional diesel combustion mode even for the most delayed SOI. Diesel and e-diesel show very similar ID values and, as shown, it is possible to obtain totally premixed combustion for delayed injection angles. E-diesel shows higher premixed proportion than diesel due to the large volatility of ethanol, which fastens the vaporization of the fuel. In every case, both $I D$ and the percentage of premixed combustion slightly decreases from 12 deg bTDC to 4 deg bTDC and increases sharply after that angle.
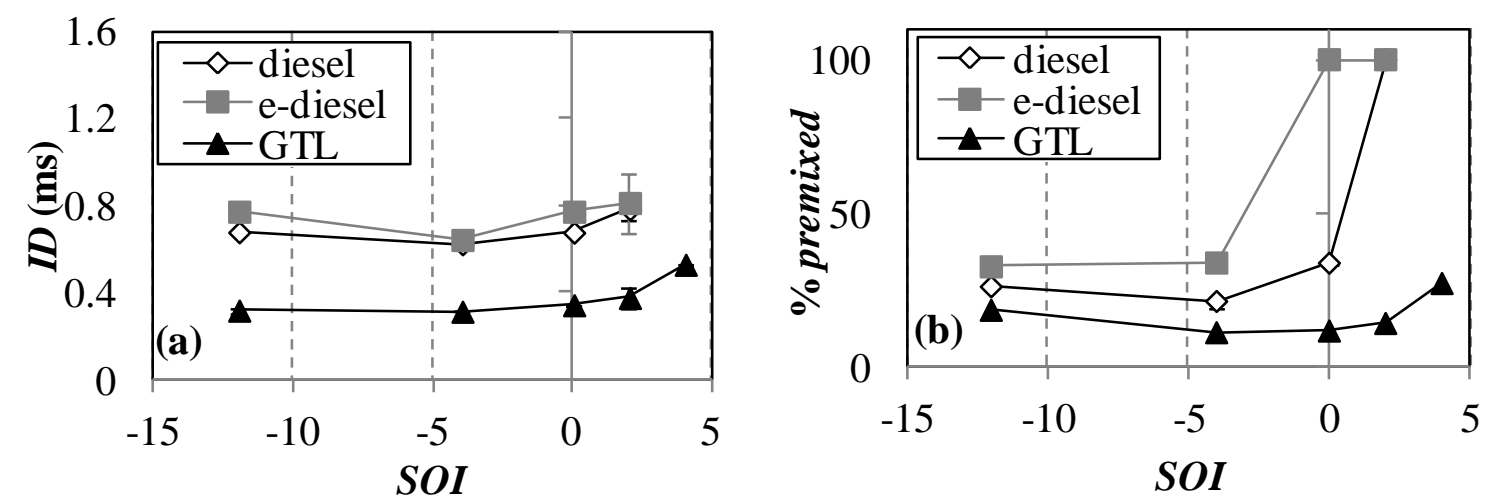

Figure 4. Global results from the $H R R$ traces a) Ignition delay b) percentage of premixed combustion

Figure 5 shows, as an example, the heat release traces from the experiments carried out at 2 deg aTDC. As observed, the latest portion of the combustion process (identified as the mixing-control stage by the Musculus et al., (2013) conceptual model) is very similar for the three fuels. However, while GTL shows traditional diesel combustion, both diesel and e-diesel show a fully premixed combustion with two separate heat release stages. The first one corresponds to the low temperature oxidation regime, and it takes place around $8 \mathrm{deg}$ bTDC. After that, the second stage or main combustion appears as a consequence of the sudden production of very reactive radicals from branching reactions (e.g the dissociation of hydrogen peroxide into two hydroxyl radicals). 


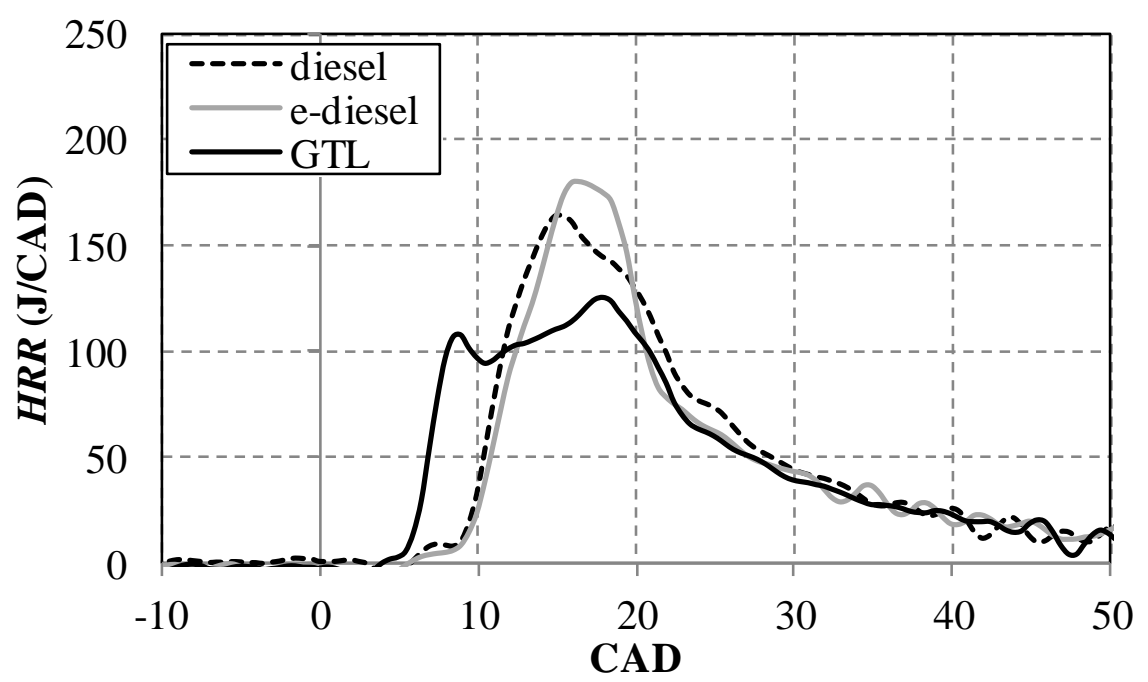

Figure 5. HRR traces from 2 deg aTDC experiments for the three fuels tested

\subsection{Performances}

E-diesel shows the highest brake fuel specific consumption (BFSC) for all the conditions analyzed, while GTL shows the lowest, as can be seen in Figure 6a. This result agrees with the energy content of each fuel. However, if the brake thermal efficiency $\left(\eta_{e}\right)$ is analyzed, conclusions are different (the energy content has no influence on $\eta_{e}$ ), as can be observed in Figure $6 \mathrm{~b}$. In this case, GTL shows slightly lower performance for SOI before TDC, while it becomes the most efficient from TDC. This can be explained considering that, for the analyzed values of SOI before TDC, a delay in the ignition contributes to center the combustion and, consequently, increases slightly the efficiency (as in the case of e-diesel). For the cases using delayed $\mathrm{SOI}$ the trend is opposite (shorter delays lead to a more centered combustion) and, for that reason, GTL shows higher values for $\eta_{e}$.
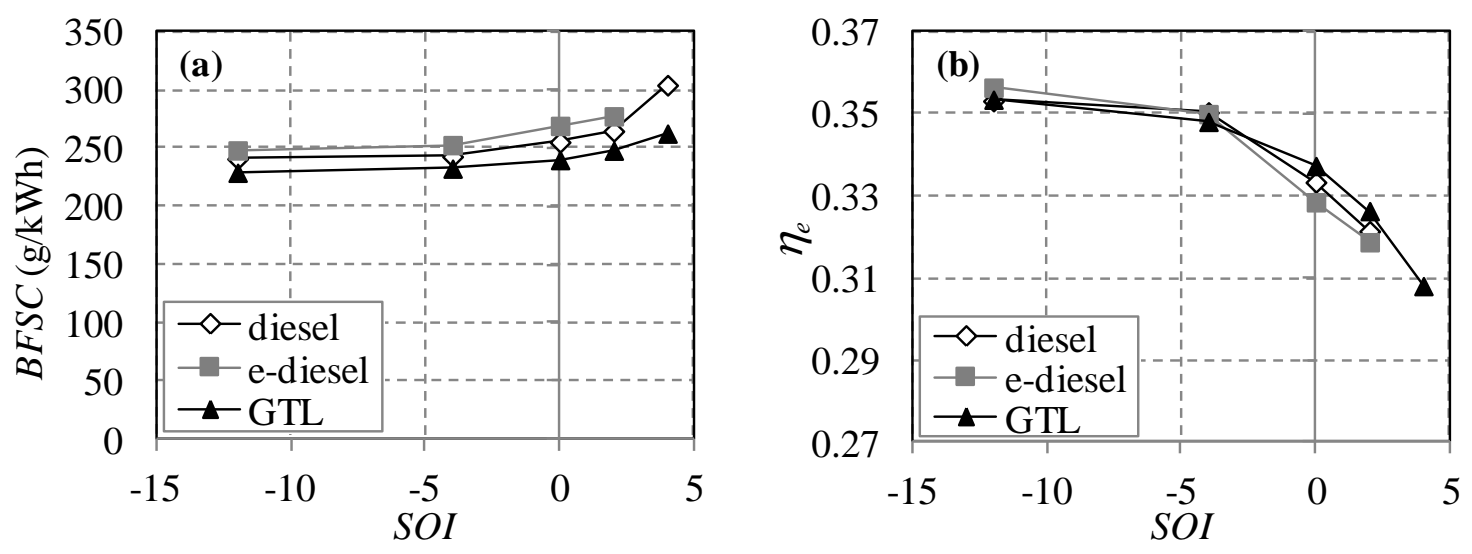

Figure 6. Effect of SOI on BFSC and brake thermal efficiency

\subsection{Hydrocarbons and $\mathrm{CO}$}

As can be observed in Figure 7, a delay in the start of injection causes a dramatic increase in unreacted or partially oxidized compounds, such as total hydrocarbons (THC) or CO, specially for SOI close to TDC or later. At most of the studied operating conditions, e-diesel shows the highest emissions, while GTL the lowest. The main sources of both compounds are the regions of the combustion chamber where either the temperature is not enough (such as the regions close to the wall) or the local equivalence ratio is too lean for a complete combustion. Thus, there is a direct relationship between the mixing degree and the amount of $\mathrm{THC}$ and $\mathrm{CO}$ emitted. As derived when comparing Figure $4 \mathrm{~b}$ and Figure 7 , the 
results are consistent (higher \% premixed lead to higher CO and THC emissions), although the differences between diesel and e-diesel are higher than expected. This latter aspect can be attributed to the properties of ethanol, a molecule with very low tendency to autoignite (in fact, it is used as an antiknock compound in gasoline-like fuels) and thus, higher tendency to form unburned or partially burned compounds.
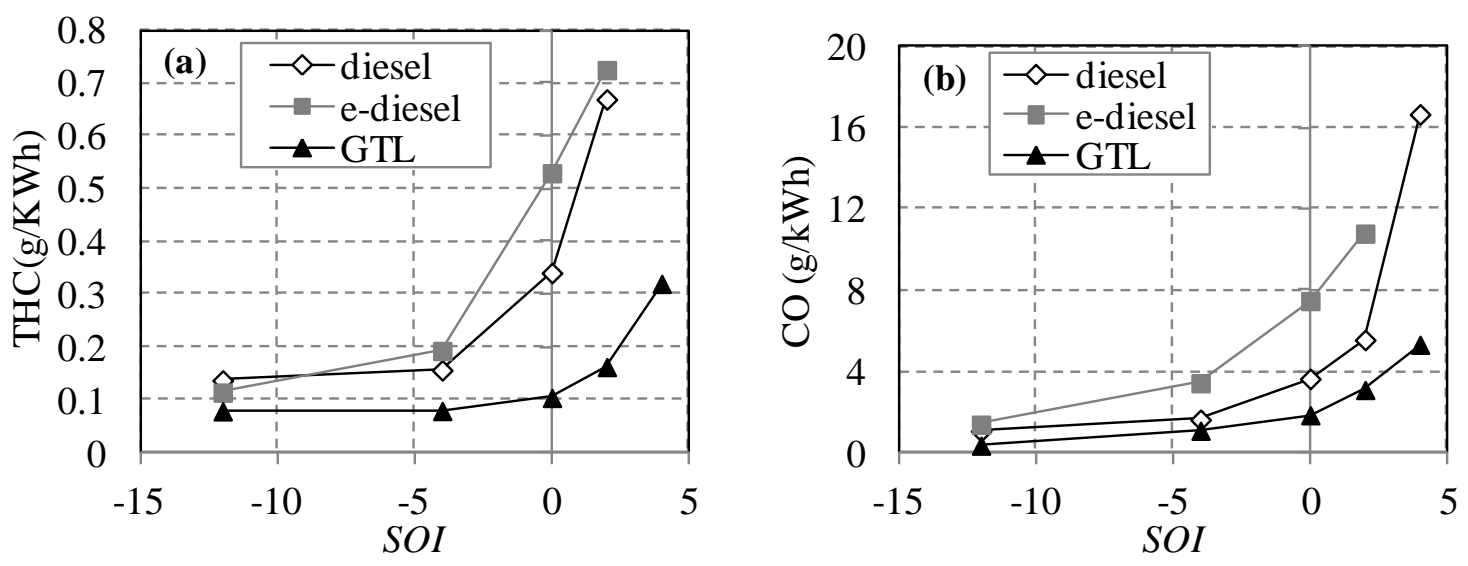

Figure 7. Effect of $\mathrm{SOI}$ in $\mathrm{THC}$ and $\mathrm{CO}$ emissions

\subsection{NOx and Particulate matter (PM)}

Figure 8a shows a decrease in the NOx emissions when delaying the injection as a consequence of the lower combustion temperatures. For all the SOI values, diesel shows the highest NOx emissions while ediesel the lowest. The differences among fuels can be attributed to the local conditions reached during combustion. On the one side, adiabatic combustion temperatures (and thus local temperatures) are the highest for diesel and the lowest for GTL. On the other side, the high enthalpy of vaporization of the ethanol causes lower local temperatures prior to combustion. The combination of both effects leads to the observed trends.
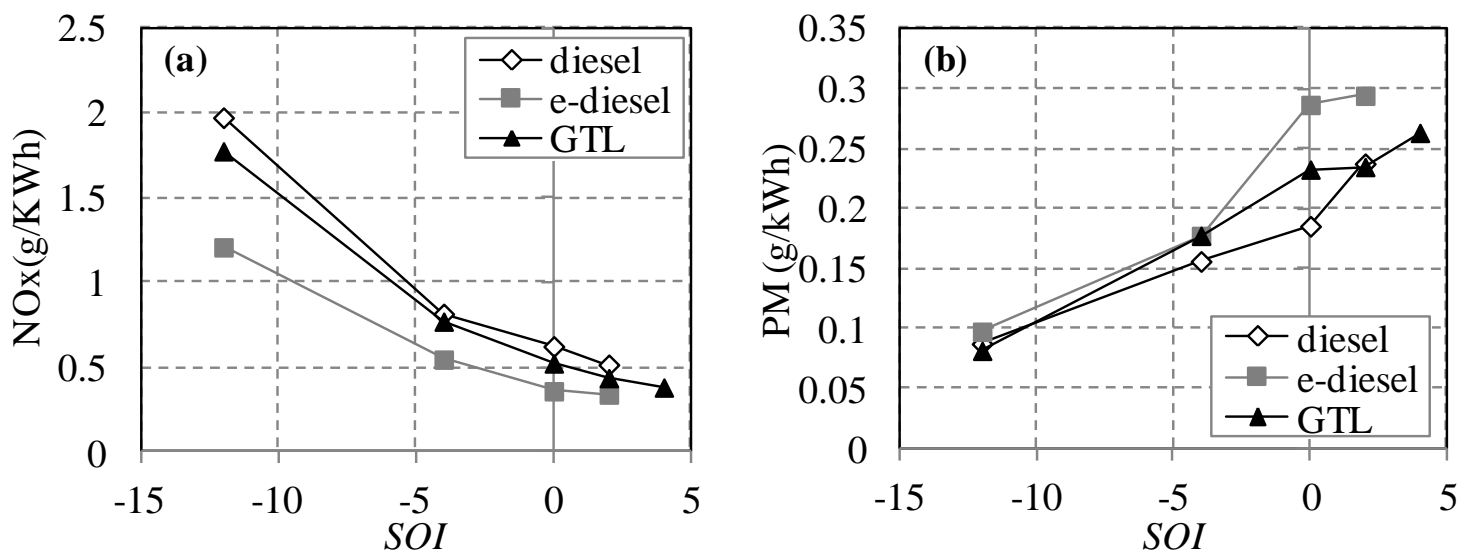

Figure 8. Effect of SOI in NOx and PM emissions

It can be observed in Figure $8 \mathrm{~b}$ that the more delayed the $\mathrm{SOI}$, the higher the amount of PM formed. As said before, the analysis of heat release has shown fully premixed conditions at SOI= 2 deg aTDC and, under these conditions, several authors (Jacobs et al., 2007; Fang et al., 2009; Karra et al., 2008; Genzale et al., 2009) have proved a reduction of the PM emissions due to locally leaner mixtures when compared to a conventional diesel-mode. However, an increase in the PM emissions has been obtained in this work. All the fuels show the same trends and, additionally, those trends are consistent with the 
particle size distributions provided by the SMPS. As shown in Figure 9, a delay in the SOI increases the number of particles, although keeping similar size distribution.
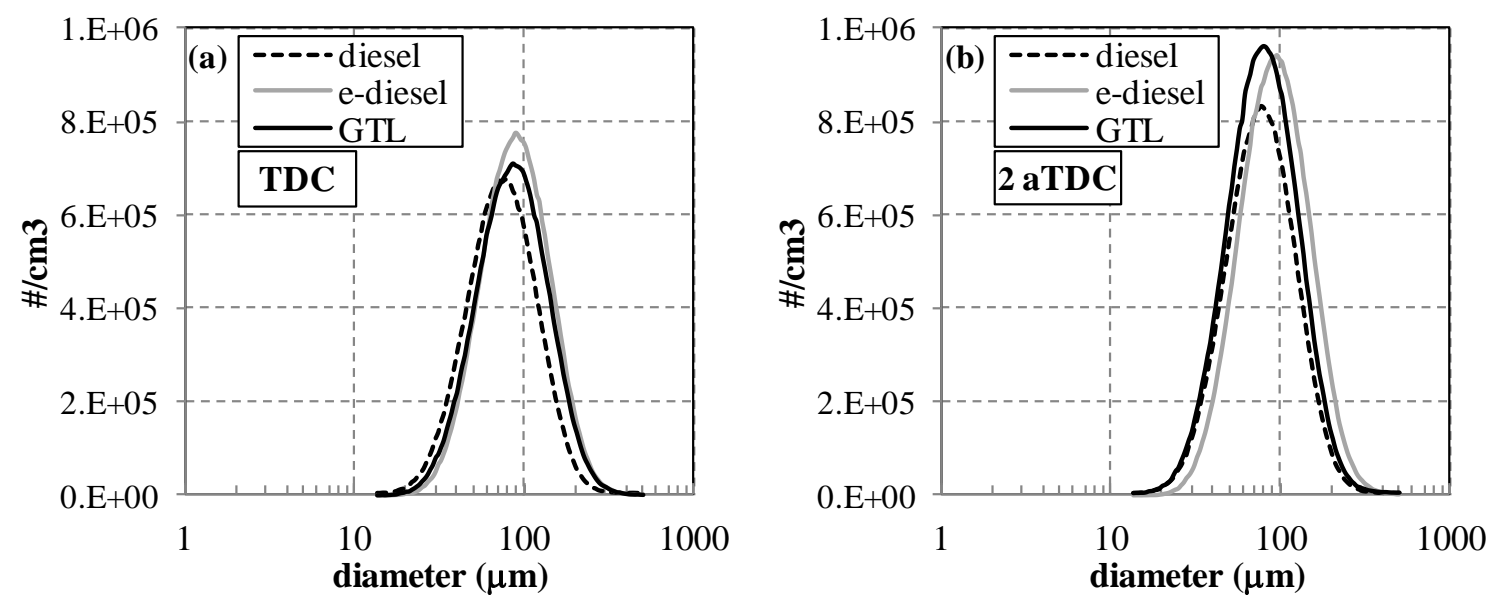

Figure 9. Effect of $S O I$ in particle size distribution (a) $S O I=T D C$ (b) $S O I=2$ deg aTDC

The observed increase of PM for delayed SOI angles could be caused by the balance between the soot formation and destruction rates. An increase in the premixing phase allows to avoid the soot formation zone in the $\phi-T$ graph, as stated by Akihama, (2001). However, depending on the EGR rate, the presence of inert gases can reduce the soot oxidation rate and increase the residence time of the soot in the jet fuel, both reasons finally resulting in an increase of the emitted PM. Dec, (2009) suggests that an increase of soot emission occurs for $A / F$ ratios from 40 to 23 . The engine torque selected for the experiments has been relatively low, and it corresponds to an overall $A / F$ ratio of approximately 30 . For these cases, soot oxidation is more highly reduced than soot formation rate when delaying $\mathrm{SOI}$, thus resulting in an increase of particles emission.

Diesel fuel shows the lowest emissions of PM followed by GTL and finally e-diesel. This is a surprising result since the composition of diesel fuel contains approximately one third of aromatics (which are soot precursors), while GTL is a mixture of paraffins (with no aromatics in its composition), and e-diesel includes ethanol which has been previously proved to reduce PM emissions (Lapuerta et al., 2009). The highest differences between fuels are observed for delayed SOI (from TDC). For those cases, brake thermal efficiency has been deteriorated (Figure 6), especially for diesel and e-diesel, which results on longer injection duration and consequently higher soot formation. Besides, the cooling effect of ethanol injection also contributes to lower local combustion temperatures and, thus, to inhibits soot oxidation. Finally, it should be also considered that GTL shows a conventional combustion process even for the most delayed SOI, thus with a higher tendency to form soot. As a balance between all the phenomena commented, diesel fuel shows the best trade-off between them while e-diesel the worst.

\section{Conclusions}

Results obtained in a heavy duty single-cylinder engine have proved the possibility to obtain almost full premixed combustion using conventional diesel and e-diesel, while the use of GTL leads to conventional diesel combustion even for very delayed SOI. The use of delayed SOI decreases the break thermal efficiency, this effect being especially significant for e-diesel due to its lower cetane number. THC and CO emissions are dramatically increased for SOI from TDC, especially for e-diesel due to its lower tendency to autoignitite. A delay in the injection also causes a reduction on NOx emissions for all the tested fuels. An increase in PM emissions has been obtained when delaying $\mathrm{SOI}$ due to the low overall equivalence ratio tested, thus inhibiting the soot oxidation process (this aspect being especially important for e-diesel due also to the lower in-cylinder temperature). 
Tests using e-diesel suggest that it can be a very promising fuel for its use under LTC conditions. Its low autoignition tendency together with the high volatity of ethanol lead to full premixed combustion for $\mathrm{SO}$ values more advanced than the other fuels. As a consequence, lower THC and CO emissions and a better brake thermal efficiency may be obtained. On the contrary, GTL properties, specially its very high cetane number, lead to conventional diesel combustion even for high EGR rates and very delayed SOI, making this fuel less suitable for LTC derived from the use of late injection.

\section{Acknowledgments}

The authors wish to acknowledge the Spanish Ministry of Science and Innovation for the financial support through the project CINBIOLT (reference code: Ref. TRA2010-18876). Dr. J. Sanz-Argent would also like to acknowledge the Universidad de Castilla-La Mancha for providing his funding through CYTEMA professorship. The authors wish to acknowledge the companies Sasol and Abengoa-Bioenergy for supplying some of the fuels tested.

\section{References}

Akihama K., Takatori Y., Inagaki K., Sasaki S. and Dean A.M. (2001), Mechanism of the Smokeless Rich Diesel Combustion by Reducing Temperature, SAE paper 2001-01-0655.

Dec J.E. (1997), A conceptual model of DI Diesel combustion based on laser-sheet imaging, SAE Transactions, 106, 1319-1348.

Dec J.E. (2009) Advanced compression-ignition engines-understanding the in-cylinder processes. Proceedings of the Combustion Institute, 32, 2727-2742.

Fang T., Coverdill R.E., Lee C-F.F. and White R.A. (2009), Air-fuel mixing and combustion in a small-bore direct injection optically accessible diesel engine using a retarded single injection strategy, Fuel, 88, 2074-2082.

Fang T., Lin Y-C, Foong T-M and Lee C-F (2008), Reducing NOx Emissions from a Biodiesel-Fueled Engine by Use of Low-Temperature Combustion, Environmental Science \& Technology, 42, 8865-8870.

Genzale C., Reitz R. and Musculus M. (2010), Optical Diagnostics and Multi-Dimensional Modeling of Spray Targeting Effects in Late-Injection Low-Temperature Diesel Combustion, SAE Int. J. Engines, 2(2), 150-172.

Jacobs T.J. and Assanis D.N. (2007), The attainment of premixed compression ignition low-temperature combustion in a compression ignition direct injection engine, Proceedings of the Combustion Institute, 31, 2913-2920.

Kalghatgi G.T., Risberg P. and Ångström H-E. (2006), Advantages of fuels with high resistance to auto-ignition in late-injection, low-temperature, compression ignition combustion, SAE paper 2006-01-3385.

Karra P.K., Veltman M.K. and Kong S-C. (2008), Characteristics of engine emissions using biodiesel blends in lowtemperature combustion regimes, Energy \& Fuels, 22, 3763-3770.

Kimura S., Aoki A., Ogawa H., Muranaka, S. and Enomoto Y. (1999), New combustion concept of ultra-clean and high-efficiency small DI diesel engines, SAE paper, 1999-01-3681.

Lapuerta M., Armas O. and García-Contreras R. (2009), Effect of Ethanol on Blending Stability and Diesel Engine Emissions, Energy Fuels, 23, 4343-4354.

Lapuerta M., Armas O. and Hernandez J.J. (1999), Diagnosis of DI Diesel combustion from in-cylinder pressure signal by estimation of mean thermodynamic properties of the gas, Applied Thermal Engineering, 19(5), 513-529.

Musculus M.P.P, Miles P.C. and Picket L.M. (2013), Conceptual models for partially premixed low-temperature diesel combustion, Prog. Energ Combust Sci., 39, 246-283.

Onishi S., Hong Jo S., Shoda K., Do Jo P. and Kato S. (1979), Active thermo-atmosphere combustion (ATAC) - A new combustion process for internal combustion engines, SAE paper 790501.

Thring R. (1989), Homogenous-charge Compression Ignition (HCCI) Engine, SAE paper 892068.

Zhao F.F., Asmus T.W., Assanis D.N., Dec J.E., Eng J.A. and Najt P.M. (editors) (2003), Homogeneous Charge Compression Ignition ( $\mathrm{HCCl}$ ) engines. SAE International. 